\title{
Rising incidence of breast cancer among female cancer survivors: implications for surveillance
}

\author{
I Soerjomataram ${ }^{*, 1,2}$, WJ Louwman ${ }^{2}$, LEM Duijm ${ }^{3}$ and JWW Coebergh ${ }^{1,2}$ \\ 'Department of Public Health, Erasmus MC, PO Box 2040, 3000 CA Rotterdam, The Netherlands; ${ }^{2}$ Comprehensive Cancer Centre South, PO Box 231 , \\ 5600 AE Eindhoven, The Netherlands; ${ }^{3}$ Department of Radiology, Catharina Hospital, PO Box 1350, 5602 ZA Eindhoven, The Netherlands
}

The number of female cancer survivors has been rising rapidly. We assessed the occurrence of breast cancer in these survivors over time. We computed incidence of primary breast cancer in two cohorts of female cancer survivors with a first diagnosis of cancer at ages $30+$ in the periods 1975-1979 and 1990-1994. Cohorts were followed for 10 years through a population-based cancer registry. Over a period of 15 years, the incidence rate of breast cancer among female cancer survivors increased by $30 \%$ (agestandardised rate ratio (RR-adj): 1.30; 95\% Cl: I.03- I.68). The increase was significant for non-breast cancer survivors (RR-adj: I.4I, 95\% Cl: 1.04-2.75). During the study period, the rate of second breast cancer stage II tripled (RR-adj: 3. I0, 95\% Cl: I.73-5.78). Nonbreast cancer survivors had a significantly $(P$ value $=0.005)$ more unfavourable stage distribution $(62 \%$ stage II and III) than breast cancer survivors (32\% stage II and III). A marked rise in breast cancer incidence among female cancer survivors was observed. Research to optimise follow-up strategies for these women to detect breast cancer at an early stage is warranted.

British Journal of Cancer (2009) 1 00, 77-81. doi:10.1038/sj.bjc.66048I6 www.bjcancer.com

Published online 9 December 2008

(c) 2009 Cancer Research UK

Keywords: female survivors; second primary cancer; breast neoplasm; trend

Breast cancer is the most common cancer among women in general, but also among women who were previously diagnosed with any type of cancer (Mariotto et al, 2007). During the past three decades, a fourfold increase in the incidence of contralateral breast cancer has been reported, which is much higher than that of first primaries (Louwman et al, 2008). However, in the same period, a $9 \%$ decrease in the incidence of second breast cancer among former breast cancer patients was reported in the United States of America ( $\mathrm{Yu}$ et al, 2006). The increasing prevalence of patients ever diagnosed with cancer should theoretically result in an increase in the incidence of new primary cancer (Fraumeni et al, 2006), that is, breast cancer among cancer survivors. Changes in female reproductive behaviour and lifestyle, that underlie the increasing trend of first breast cancer, may also affect the increased risk of a second breast cancer (Dignam et al, 2003; Largent et al, 2007). Furthermore, cancer survivors are exposed to additional carcinogenic factors such as high-dose radiation for the first cancer (van Leeuwen and Travis, 2005). Using data from a longstanding cancer registry in southern Netherlands, we investigated the incidence of breast cancer among cancer survivors since 1975. We assessed the change in incidence of a second breast cancer over time according to age, stage and type of treatment of the first cancer.

\footnotetext{
*Correspondence: Dr I Soerjomataram; E-mail: i.soerjomataram@erasmusmc.nl Received 31 March 2008; revised 7 September 2008; accepted 15 November 2008; published online 9 December 2008
}

\section{MATERIALS AND METHODS}

Data on cancer patients were obtained from the Eindhoven Cancer Registry (ECR), located in the south of Netherlands. This is a population-based registry with follow-up data since 1970, including clinical aspects such as stage and initial treatment. The cancer registry regularly receives lists of new cancer cases from the pathology and haematology departments in the region. In addition, lists of all hospitalised cancer patients were obtained, comprising data from hospital medical records. In the ECR, active follow-up of vital status is conducted through linkage with municipal population registries and the Central Bureau for Genealogy. Eindhoven Cancer Registry is a long-standing cancer registry with highquality data, as indicated by the high proportion of histologically verified cases. (Curado et al, 2007) Furthermore, the proportion of new cases identified through death certificates or autopsy only is $0 \%$, indicating efficient case finding (Curado et al, 2007). The coverage area of the registry in the south of the Netherlands has gradually increased, covering about 0.9 million people between 1975 and 1985 and over 2 million people since 1988.

\section{Data analysis}

The change in breast cancer incidence among cancer survivors over time was calculated using the fixed inception cohort method (Yu et al, 2006). We defined two patient cohorts: women diagnosed with a primary cancer between 1975 and 1979 and those diagnosed between 1990 and 1994. We included all cancer types diagnosed in women aged 30 years or more within the given periods, excluding premalignant or in situ cancer and basal cell carcinoma of the skin. Only patients who survived 6 months or longer were included in the cohort. The rules for multiple primary cancers from the International Agency for Cancer Research were used (Working 
Group Report, 2005). Based on these rules, a person can have only one cancer per organ or pair of organs except when multiple tumours within an organ have a different histology. For breast cancer, two tumours of different laterality but of the same morphology are registered separately (2005). The follow-up time extended from the date of the initial cancer diagnosis to the date of a second cancer, death, loss to follow-up or end of the study, whichever occurred first. We applied a 10-year follow-up for each patient cohort. Thus, the 1975-1979 cohort was followed until 1989 and the 1990-1994 cohort until 2004. Person-years contributed by each survivor were calculated to compute incidence rates per 100000 person-years. Adjustment for age was performed by calculating predicted rates of expected new breast cancer incident cases, assuming identical age composition (entered in 5year age categories) of the first and second cohort. We used Poisson regression using Proc genmod in SAS. To compare the two periods, rate ratios of breast cancer and their 95\% confidence intervals (95\% CI) were computed taking the earlier cohort (those diagnosed with first cancer between 1975-1979) as reference (Breslow and Day, 1987).

To identify the factors causing differences in rates over time, we stratified according to type of first primary cancer (breast and non-breast cancer) and treatment of the first primary (surgery, radiotherapy with or without surgery, systemic therapy with or without surgery, radiotherapy and systemic therapy with or without surgery and no therapy).

Finally, incidence rates of breast cancer in female survivors were calculated stratifying by age (30-49 years, $50-74$ years and $75+$ years) and TNM-stage (Sobin and Fleming, 1997). This provides insight on the role of breast cancer screening in trends of breast cancer among survivors.

\section{RESULTS}

Within 10 years of the first cancer diagnosis, 100 of 3368 (3\%) and 182 of 5507 (3\%) female cancer survivors diagnosed in the 1970 s and in the 1990s, respectively, were subsequently diagnosed with breast cancer. Compared to patients diagnosed in the 1970s, cancer survivors diagnosed with a first cancer in the 1990 s were 2.1 years older at first diagnosis and were more likely to have received systematic treatment (combined with either surgery or radiotherapy; Table 1). In both periods, digestive and urogenital cancers were the most common first non-breast cancer tumours.

Compared with the first period, a 30\% increase in breast cancer incidence was observed in female cancer survivors (age-adjusted rate ratio (RR-adj): 1.30; 95\% CI: $1.03-1.68$; Table 2). Most marked increase in incidence of breast cancer was found among women previously diagnosed with non-breast cancer (RR-adj: $1.41 ; 95 \% \mathrm{CI}$ : $1.04-2.75)$. There appeared to be a similar increase in breast cancer incidence across most treatment groups, albeit with wide confidence intervals. After adjusting for age, treatment and type of first cancer, the increase over time in breast cancer incidence among survivors became larger (RR-adj: 1.42; 95\% CI: $1.11-1.83$ ). This corresponded to a 201 excess cases per 100000 female cancer survivors.

Table 3 shows that the increase over time in the incidence of breast cancer among female cancer survivors was similar for all age groups. The incidence rate tripled for stage II breast cancer (RR-adj: 3.10; $95 \%$ CI: $1.73-5.78$ ) between the late 1970 s and the early 1990 s.

Figure 1 illustrates the stage distribution of breast cancer for female survivors diagnosed with a first cancer in 1990-1994 categorised according to age at second breast cancer diagnosis and type of first cancer. A significant difference in stage distribution was found for the non-breast cancer survivors compared to those with a previous breast cancer. The proportion of second breast cancer stages II and III among non-breast cancer survivors was $62 \%$, compared to only $32 \%$ among breast cancer survivors $(P$ value $=0.005)$.
Table I Characteristics of female cancer survivors diagnosed in 1975 1979 and in 1990-1994 with a 10-year follow-up

\begin{tabular}{|c|c|c|c|c|}
\hline \multirow[t]{2}{*}{$\begin{array}{l}\text { Period of first primary cancer diagnosis } \\
\text { Number of cancer survivors } \\
\text { Women-years of follow-up } \\
\text { Mean age at first cancer (years) } \\
\text { Mean follow-up time (years) }\end{array}$} & \multicolumn{2}{|c|}{$\begin{array}{c}1975-1979 \\
3368 \\
19287 \\
60.5 \\
5.7\end{array}$} & \multicolumn{2}{|c|}{$\begin{array}{l}1990-1994 \\
5507 \\
26913 \\
62.7 \\
4.9\end{array}$} \\
\hline & $\mathbf{N}$ & $\%$ & $\mathbf{N}$ & $\%$ \\
\hline \multicolumn{5}{|l|}{ Age at diagnosis of first cancer } \\
\hline $30-49$ years & 791 & 23 & 1200 & 22 \\
\hline $50-74$ years & 2070 & 61 & 3086 & 56 \\
\hline $75+$ years & 507 & 15 & 1221 & 22 \\
\hline \multicolumn{5}{|l|}{ Treatment of first cancer } \\
\hline Surgery & 1417 & 42 & 2248 & 41 \\
\hline Radiotherapy \pm surgery & 1245 & 37 & 1450 & 26 \\
\hline Systemic therapy \pm surgery & 322 & 10 & 767 & 14 \\
\hline Radiotherapy+systemic therapy \pm surgery & 220 & 6 & 760 & 14 \\
\hline No therapy & 164 & 5 & 282 & 5 \\
\hline \multicolumn{5}{|l|}{ Type of first cancer } \\
\hline Breast cancer & 1436 & 43 & 2199 & 40 \\
\hline Non-breast cancer ${ }^{a}$ & 1932 & 57 & 3308 & 60 \\
\hline
\end{tabular}

$N$ indicates number of cases and \% indicates column's percentage. ${ }^{a}$ First non-breast cancer in 1970s consisted of 3\% respiratory cancers, $40 \%$ digestive cancers, $34 \%$ urogenital cancers (of which 24\% (155 cases) were ovarian cancer cases), 9\% haematopoietic cancers (Hodgkin lymphoma 19 cases) and 15\% other cancers, and in 1990s $7 \%$ respiratory cancers, 33\% digestive cancers, 30\% urogenital cancers (of which $24 \%$ (238 cases) were ovarian cancer cases), 10\% haematopoietic cancers (Hodgkin lymphoma 17 cases) and 19.3\% other cancers.

\section{DISCUSSION}

In the general population, a $20 \%$ increase in the incidence of breast cancer has been reported over a 15-year period. (Louwman et al, 2008) In the same period, we observed an increase of $30 \%$ in the incidence of breast cancer among female cancer survivors. This increase was largest for non-breast cancer survivors and for second breast cancer stage II. The relatively large increase in breast cancer incidence among cancer survivors may be due to several factors: (1) The breast cancer early detection program (mass screening) that started in the early 1990s in the Netherlands; (2) application of more combined therapies with higher carcinogenic potential and (3) lifestyle, reproductive and hormonal factors, such as a longer interval between menarche and date of first birth, use of hormonal replacement therapy and alcohol use.

In the early 1990s, biennial mass screening for breast cancer was implemented for all women aged 50-69 years. In 1998, this program was expanded to include women up to the age of 75 (Verbeek and Broeders, 2003). Due to the intensified use of mammography for mass screening, the incidence of breast cancer increased by about 30\% (Fracheboud et al, 2004) and may thus also be responsible for the increased incidence of breast cancer among cancer survivors. Consistently, we observed a significant increase in the proportion of female survivors diagnosed with early breast cancer (stages I and II being $54 \%$ in 1970 s vs $76 \%$ in 1990s). On the other hand, we observed a similar increase in the incidence of breast cancer among survivors that do not fall in the screening age-target group ( $<50$ and $>74$ years) to those targeted by screening (50-74 years). Furthermore, the increase of breast cancer incidence among female survivors is larger than that of the general population. This suggests that screening cannot fully account for this increase. Other breast cancer risk factors are likely to have contributed to this increase, including older age at first childbirth, fewer children, alcohol and other determinants of postmenopausal obesity (Althuis et al, 2005). 
Trend of breast cancer in female cancer survivors

Table 2 Number $(N)$ and age-standardised incidence rates of breast cancer per 100000 women-years for female cancer survivors ${ }^{\mathrm{a}}$

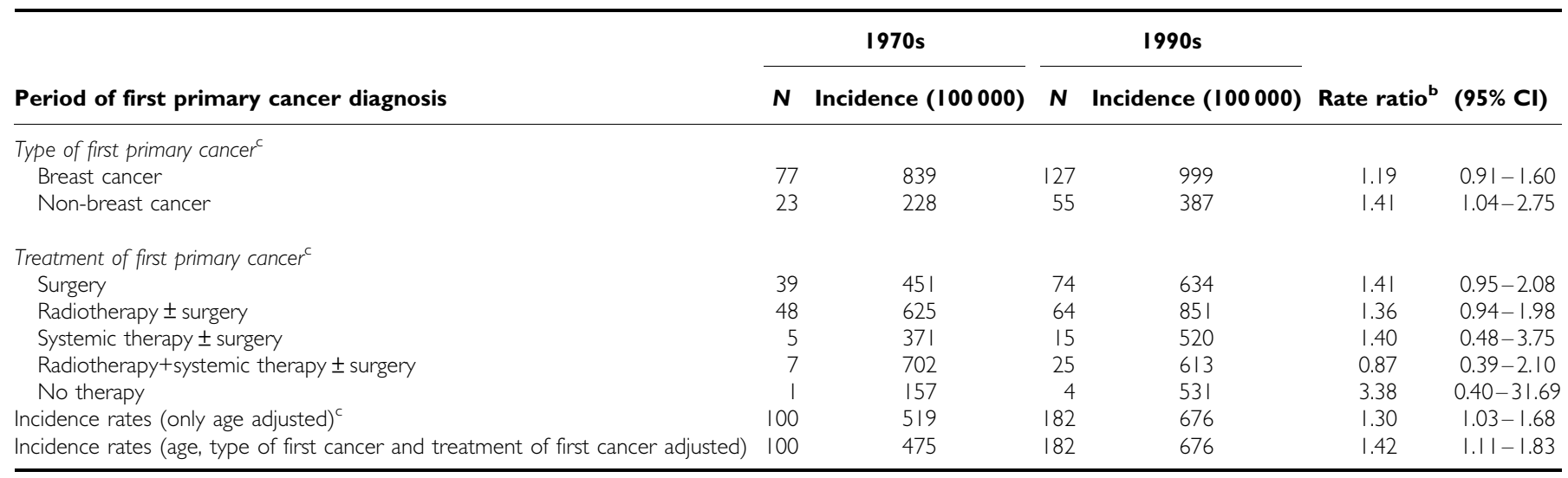

$\mathrm{N}$ indicates number of cases. ${ }^{\mathrm{a}}$ Female cancer survivors are both breast cancer and non-breast cancer survivors. ${ }^{\mathrm{b}}$ Rate ratio compares incidence rate in 1990 s with incidence rate in 1970s. 'Age adjusted.

Table 3 Incidence rates of breast cancer per 100000 women-years for female cancer survivors ${ }^{\mathrm{a}}$ according to age and stage of breast cancer (second primary) in 1970s and 1990s

\begin{tabular}{|c|c|c|c|c|c|c|}
\hline \multirow{2}{*}{$\begin{array}{l}\text { Period of first primary cancer diagnosis } \\
\text { Mean age at breast cancer (years) }\end{array}$} & \multicolumn{2}{|r|}{$\begin{array}{c}1970 \mathrm{~s} \\
60.8\end{array}$} & \multicolumn{2}{|r|}{$\begin{array}{c}1990 \mathrm{~s} \\
63.2\end{array}$} & \multirow[b]{2}{*}{ Rate ratio ${ }^{\mathbf{b}}$} & \multirow[b]{2}{*}{$(95 \% \mathrm{Cl})$} \\
\hline & $\mathbf{N}$ & Incidence $(100000)$ & $N$ & Incidence $(100000)$ & & \\
\hline \multicolumn{7}{|c|}{ Age at breast cancer (second primary - age-specific rates) } \\
\hline $30-49$ years & 23 & 678 & 43 & 887 & 1.3 & $0.8-2.2$ \\
\hline $50-74$ years & 61 & 509 & 94 & 615 & 1.2 & $0.9-1.7$ \\
\hline $75+$ & 16 & 409 & 45 & 664 & 1.6 & $0.9-2.9$ \\
\hline \multicolumn{7}{|l|}{ Stage of breast cancer (second primary) ${ }^{c}$} \\
\hline । & 41 & 209 & 82 & 305 & 1.46 & $0.99-2.11$ \\
\hline$\|$ & 13 & 68 & 57 & 212 & 3.10 & $1.73-5.78$ \\
\hline III & 11 & 58 & 18 & 67 & 1.16 & $0.56-2.50$ \\
\hline IV & 9 & 46 & 14 & 52 & 1.14 & $0.50-2.65$ \\
\hline Unknown & 26 & 140 & 11 & 41 & 0.29 & $0.14-0.59$ \\
\hline
\end{tabular}

$\mathrm{N}$ indicates number of cases. ${ }^{a}$ Female cancer survivors are both breast cancer and non-breast cancer survivors. ${ }^{b}$ Rate ratio compares incidence rate in 1990 s with incidence rate in 1970s, if adjusted rates are presented than rate ratio is based on the standardised rates. ${ }^{c}$ Age adjusted.

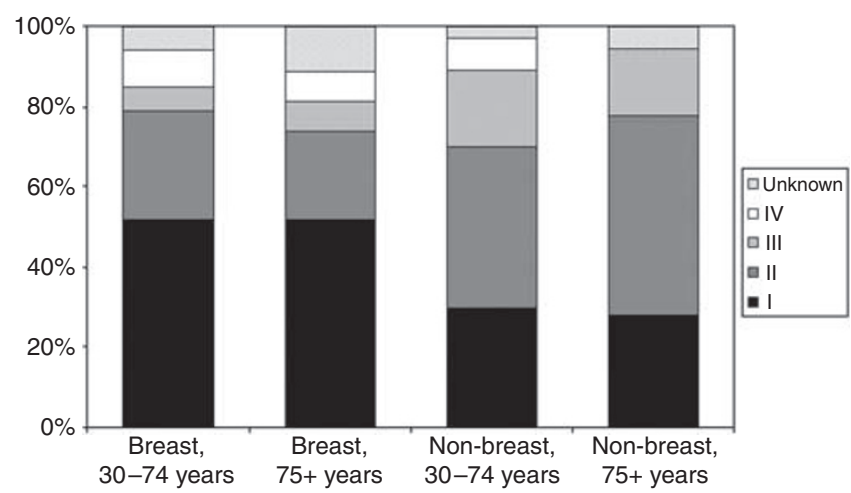

Type of the first cancer and age at the second breast cancer

Figure I Stage distribution of breast cancer in female cancer survivors diagnosed with a first cancer in 1990-1994 according to type of first cancer and age at (second) breast cancer diagnosis.

In the Netherlands, patients with breast cancer receive enhanced surveillance: annual mammography until the age of 60 , followed by a biennial mammography up to the age of 74 (NABON Nationaal Borstkanker Overleg Nederland, 2005). This intense surveillance pattern is likely to explain the better stage distribution compared with the non-breast cancer survivors. In addition, it may also contribute to an increase in detection rates for slow-growing tumours that would have remained in the pre-clinical phase longer without screening mammography (Shen et al, 2005). Thus, breast cancer survivors are probably diagnosed more often and earlier with a low-grade breast cancer, which may require less aggressive treatment than other cancers (Moody-Ayers et al, 2000).

Changes in therapy for first primary cancer may have influenced the incidence of second breast cancer over time. Radiotherapy has been associated with an approximately $40 \%$ higher risk of developing subsequent breast cancer compared to systemic hormonal or cytotoxic treatment (Soerjomataram et al, 2005; Schaapveld et al, 2008). In addition, cancer patients who receive a high radiation dose on the chest as part of treatment have higher breast cancer risk. For example, young women with Hodgkin lymphoma may have up to $29 \%$ cumulated risk of breast cancer 30 years after treatment. (Travis et al, 2005) On the other hand, radiotherapy treatment techniques and protection of the normal tissue have improved in the last decades. In our study, we observed a similar increase in the incidence of breast cancer over time for those who were irradiated and those who only underwent surgery. The increasing incidence of breast cancer among those who were irradiated could therefore not be attributed to radiotherapy. However, because we followed patients for only 10 years, we may have missed late adverse effects of radiation (Travis, 2006). 
Although the use of systemic cancer treatment has doubled during the last 20 years, we found that the increase in the incidence of breast cancer among those who received systemic treatment was similar to surgically treated patients, whereas a decrease in incidence was expected. Studies have shown that cancer patients who have hormonal therapy (eg tamoxifen) or chemotherapy have a reduced risk of breast cancer (van Leeuwen et al, 2003; Early Breast Cancer Trialists' Collaborative_Group, 2005). A protective effect of tamoxifen on second breast cancer is most evident in the post-treatment period (Powles et al, 2007). Thus, it is possible that changes in rates over time may differ for different categories of follow-up, for example, decreasing trend of breast cancer in survivors who received tamoxifen, which is only observable 8 years after treatment. Unfortunately, we did not have sufficient power to examine trends across different follow-up periods.

In view our results the following groups may need a more intensive follow-up for breast cancer. Firstly, non-breast cancer survivors. These patients had a larger proportion of stage II breast cancer than patients who had breast cancer as a first primary cancer. Among non-breast cancer patients diagnosed in 19901994 and followed up for 10 years, $29 \%$ of second breast cancers was stage $1,44 \%$ stage $2,18 \%$ stage III and $5 \%$ stage IV. For breast cancer patients, the corresponding percentages were $52 \%$ for stage I, $26 \%$ for stage II, $6 \%$ for stage III and $9 \%$ for stage IV ( $P$ value of $\left.\chi^{2}: 0.005\right)$. Thus, although the absolute risks (2\% during 10 -year follow-up) remain small, female survivors of non-breast cancer would probably benefit from a more intensive follow-up than just the mass-screening program, such as an additional biennial clinical breast examination. (Rijnsburger et al, 2004) A second group is female survivors older than 75 years. (Boer et al, 1995) Survivors of this age group exhibited the largest increase in breast cancer incidence over time. Furthermore, compared to the general population, they had a threefold higher risk of breast cancer than the general population. (Comprehensive_Cancer_Centre, 2007) Given a worse stage distribution especially among those diagnosed with a non-breast cancer, it seems logical to extend the screening program to include older female survivors. However, mortality due to other causes is high (Hooning et al, 2006) and the existence of comorbidities would probably limit treatment choices. (Louwman et al, 2005) Furthermore, early detection increases overdiagnosis and may lead to overtreatment. In older women, this issue is greater due to the longer sojourn time of breast cancer, that is longer time in which a cancer is still asymptomatic, but already detectable by a screening test. (Fracheboud et al, 2006) Thus, a detailed cost-effectivity study, preferably adjusting for Quality of Life, is warranted. A last group is cancer survivors younger than 50 years. Although the incidence of breast cancer has not increased much over time, incidence was highest for survivors aged 30-49 years. This group may merit the same screening regimen as women with a genetic predisposition towards breast cancer, that is with an MRI.

It should be warranted that besides the apparent beneficial effect that is detecting cancer at an early stage, screening has also harmful effects. Therefore, a decision to screen should always weigh the benefit, harm and cost. (Fracheboud et al, 2006) The main unfavourable effect is overdiagnosis, that is diagnosis of cancers that would not have been detected if there had not been screening. This leads to a loss of quality of life, because the person has to live with a cancer diagnosis and unnecessary treatment. Furthermore, early detection using mammography may increase the lifetime exposure to radiation and hence the breast cancer risk. However, simulation studies have shown that screening prevented more deaths from breast cancer than it induced. (Beemsterboer et al, 1998).

In summary, we found a significant increase in the incidence of breast cancer among female cancer survivors, especially for nonbreast cancer survivors. The increase in second breast cancers was most striking for stage II cancers. Our findings suggest that there is ample room for improvement in follow-up strategies to detect breast cancer at an early stage in this group.

\section{ACKNOWLEDGEMENTS}

The work for this article is financed by the Eindhoven Cancer Registry and the European Union through the Eurocadet project (SP23-CT-2005-006528).

\section{REFERENCES}

Althuis MD, Dozier JM, Anderson WF, Devesa SS, Brinton LA (2005) Global trends in breast cancer incidence and mortality 1973-1997. Int J Epidemiol 34: 405-412

Beemsterboer PM, Warmerdam PG, Boer R, de Koning HJ (1998) Radiation risk of mammography related to benefit in screening programmes: a favourable balance? J Med Screen 5: $81-87$

Boer R, de Koning HJ, van Oortmarssen GJ, van der Maas PJ (1995) In search of the best upper age limit for breast cancer screening. Eur J Cancer 31A: $2040-2043$

Breslow NE, Day NE (1987) Statistical methods in cancer research. Volume II - The design and analysis of cohort studies. IARC Sci Publ 1-406

Comprehensive Cancer Centre (2007) Available at: www.ikcnet.nl

Curado MP, Edwards B, Shin HR, Storm H, Ferlay J, Heanue M, Boyle P (2007) Cancer incidence in five continents, Vol. IX. In IARC Scientific Publications No. 160 Chapter 2. Techniques of registration. pp 1-2, Lyon: IARC

Dignam JJ, Wieand K, Johnson KA, Fisher B, Xu L, Mamounas EP (2003) Obesity, tamoxifen use, and outcomes in women with estrogen receptorpositive early-stage breast cancer. J Natl Cancer Inst 95: 1467-1476

Early Breast Cancer Trialists' Collaborative Group (2005) Effects of chemotherapy and hormonal therapy for early breast cancer on recurrence and 15-year survival: an overview of the randomised trials. Lancet 365: $1687-1717$

Fracheboud J, Groenewoud JH, Boer R, Draisma G, de Bruijn AE, Verbeek AL, de Koning HJ (2006) Seventy-five years is an appropriate upper age limit for population-based mammography screening. Int J Cancer 118: $2020-2025$

Fracheboud J, Otto SJ, van Dijck JA, Broeders MJ, Verbeek AL, de Koning HJ (2004) Decreased rates of advanced breast cancer due to mammography screening in The Netherlands. Br J Cancer 91: 861 - 867

Fraumeni JFJ, Curtis R, Edwards BK, Tucker MA (2006) Introduction. New Malignancies Among Cancer Survivors: SEER Registries, 1973-2000. National Cancer Institute: Bethesda, MD

Hooning MJ, Aleman BM, van Rosmalen AJ, Kuenen MA, Klijn JG, van Leeuwen FE (2006) Cause-specific mortality in long-term survivors of breast cancer: a 25-year follow-up study. Int J Radiat Oncol Biol Phys 64: $1081-1091$

Largent JA, Capanu M, Bernstein L, Langholz B, Mellemkjaer L, Malone KE, Begg CB, Haile RW, Lynch CF, Anton-Culver H, Wolitzer A, Bernstein JL (2007) Reproductive history and risk of second primary breast cancer: The WECARE Study. Cancer Epidemiol Biomarkers Prev 16: 906 -911

Louwman WJ, Janssen-Heijnen ML, Houterman S, Voogd AC, van der Sangen MJ, Nieuwenhuijzen GA, Coebergh JW (2005) Less extensive treatment and inferior prognosis for breast cancer patient with comorbidity: a population-based study. Eur J Cancer 41: 779-785

Louwman WJ, Voogd AC, van Dijck JA, Nieuwenhuijzen GA, Ribot J, Pruijt JF, Coebergh JW (2008) On the rising trends of incidence and prognosis for breast cancer patients diagnosed 1975-2004: a long-term population-based study in southeastern Netherlands. Cancer Causes Control 19: $97-106$ 
Mariotto AB, Rowland JH, Ries LA, Scoppa S, Feuer EJ (2007) Multiple cancer prevalence: a growing challenge in long-term survivorship. Cancer Epidemiol Biomarkers Prev 16: 566-571

Moody-Ayers SY, Wells CK, Feinstein AR (2000) 'Benign' tumors and 'early detection' in mammography-screened patients of a natural cohort with breast cancer. Arch Intern Med 160: 1109-1115

NABON Nationaal Borstkanker Overleg Nederland (2005) Breast Cancer Treatment: National Guidelines, Vol. 2007. Vereniging van Integrale Kankercentra: Utrecht

Powles TJ, Ashley S, Tidy A, Smith IE, Dowsett M (2007) Twenty-year follow-up of the Royal Marsden randomized, double-blinded tamoxifen breast cancer prevention trial. J Natl Cancer Inst 99: 283-290

Rijnsburger AJ, van Oortmarssen GJ, Boer R, Draisma G, To T, Miller AB, de Koning HJ (2004) Mammography benefit in the Canadian National Breast Screening Study-2: a model evaluation. Int J Cancer 110: $756-762$

Schaapveld M, Visser O, Louwman WJ, Willemse PH, de Vries EG, van der Graaf WT, Otter R, Coebergh JW, van Leeuwen FE (2008) The impact of adjuvant therapy on contralateral breast cancer risk and the prognostic significance of contralateral breast cancer: a population based study in the Netherlands. Breast Cancer Res Treat 110: 189-197

Shen Y, Yang Y, Inoue LY, Munsell MF, Miller AB, Berry DA (2005) Role of detection method in predicting breast cancer survival: analysis of randomized screening trials. J Natl Cancer Inst 97: 1195-1203

Sobin LH, Fleming ID (1997) TNM classification of malignant tumors, fifth edition (1997). Union Internationale Contre le Cancer and the American Joint Committee on Cancer. Cancer 80: 1803-1804
Soerjomataram I, Louwman WJ, Lemmens VE, de Vries E, Klokman WJ, Coebergh JW (2005) Risks of second primary breast and urogenital cancer following female breast cancer in the south of The Netherlands, 1972-2001. Eur J Cancer 41: 2331 - 2337

Travis LB (2006) The epidemiology of second primary cancers. Cancer Epidemiol Biomarkers Prev 15: 2020-2026

Travis LB, Hill D, Dores GM, Gospodarowicz M, van Leeuwen FE, Holowaty E, Glimelius B, Andersson M, Pukkala E, Lynch CF, Pee D, Smith SA, Van't Veer MB, Joensuu T, Storm H, Stovall M, Boice Jr JD, Gilbert E, Gail MH (2005) Cumulative absolute breast cancer risk for young women treated for Hodgkin lymphoma. J Natl Cancer Inst 97: $1428-1437$

van Leeuwen FE, Klokman WJ, Stovall M, Dahler EC, van't Veer MB, Noordijk EM, Crommelin MA, Aleman BM, Broeks A, Gospodarowicz M, Travis LB, Russell NS (2003) Roles of radiation dose, chemotherapy, and hormonal factors in breast cancer following Hodgkin's disease. J Natl Cancer Inst 95: 971 - 980

van Leeuwen FE, Travis LB (2005) Second Cancers. Vol. 2. Cancer: Principles and Practice of Oncology. Philadelphia: Lippincott Williams and Wilkins

Verbeek AL, Broeders MJ (2003) Evaluation of The Netherlands breast cancer screening programme. Ann Oncol 14: 1203-1205

Working Group Report (2005) International rules for multiple primary cancers (ICD-0 third edition). Eur J Cancer Prev 14: 307 - 308

Yu GP, Schantz SP, Neugut AI, Zhang ZF (2006) Incidences and trends of second cancers in female breast cancer patients: a fixed inception cohort-based analysis (United States). Cancer Causes Control 17: $411-420$ 